\title{
The Mediating Effect of Organizational Climate on the Relationship between Transformational Leadership and Patient Safety: A Study on Saudi Hospitals
}

\author{
${ }^{1}$ Eqab Aiyadh Alotaibi \\ ${ }^{2}$ Rushami ZienYusoff \\ ${ }^{3}$ Abdullah Kaid Al-Swidi \\ 4Ebrahim Mohammed Al-Matari \\ 50mar Zayyan AISharqi \\ ${ }^{1}$ Ministry of HealthSaudi Arabia and School of Business Management (SBM), College of Business, \\ University Utara Malaysia, 06010 UUM, Kedah,Malaysia., Email: aldhiyabi08@yahoo.com \\ 2School of Business Management (SBM), College of Business, University Utara Malaysia, \\ 06010 UUM, Kedah,Malaysia. Email: rzy278@uum.edy.my \\ ${ }^{3}$ College of Management and Economics, Qatar University, Qatar, Email: Dr.swidi@gmail.com \\ 4Faculty of Business and Economics, Ammran University, Yemen and Othman Yeop Abdullah Graduate \\ School of Business, University Utara Malaysia, Malaysia, Email: Ibrahim_matri@yahoo.com \\ ${ }^{5}$ Faculty of Economics and Aministration, King Abdulaziz University, Saudi Arabia, Email:Oalsharqi@yahoo.com
}

\section{Doi:10.5901/mjss.2015.v6n2s1p117}

\begin{abstract}
the main aim of this paper is to investigate the mediation effect of organizational climate on the relationship between Transformational Leadership and perceived patient safety in Saudi Hospitals from the nurses perspective. Patient safety has become a significant topic among health professionals, policy makers, and the public owing to the emphasis on the reported and unreported healthcare errors that result in negative situations. A quantitative research design was employed to collect data from nurses in Saudi hospitals to examine the hypothesized model. Out of 254 questionnaires distributed only 217 questionnaires were usable for analysis. The Partial Least Squares Structural Equation Modeling (PLS-SEM) method was used to test the hypotheses. Based on the statistical results, this study supported the relationship between Transformational Leadership and organizational climate and the relationship between organizational climate and perception of patient safety. Finally, this study confirmed the full mediating effect of organizational climate on the relationship between Transformational Leadership and perception of patient safety. The findings of the study are of a great value to both theory and practice and have important implications for practitioners and policy-makers.
\end{abstract}

Keywords: Organizational climate, Patient safety, Transformational Leadership, Saudi Hospital

\section{Introduction}

Patient safety has become a significant topic among health professionals, policy makers, and the public owing to the emphasis on the reported and unreported healthcare errors that result in negative situations. Several initiatives and studies dedicated to patient safety have been conducted in the Western countries that are characterized by wellorganized healthcare systems and effectively implemented quality assurance programs (Al Rifai, 2008). In contrast, developing countries lack the infrastructure required for the implementation and lack resources to tackle patient safety. On the basis of the report of the World Health Organization (WHO, 2004), deficiencies in healthcare systems in terms of infrastructure, lack of skilled personnel and other quality issues are still prevalent in the developing countries.

Patient safety is comprised of indicators including various items in the literature and among the top of them are patient mortality, failure-to-rescue (Aiken, et al., 2003), pneumonia, pressure ulcers, erroneous medication, patients' accidental falls, and infections (Penoyer, 2010).

In an attempt to describe the potential factors affecting patient safety, it was stated that adverse events do not occur intentionally from people to hurt patients but they are attributed to the complex healthcare systems which influences the performance of the individuals(WHO, 2009). The ability of the employees to perform hinges upon a set of combined 
factors in a way that possessing greater abilities, being highly motivated and steering clear of external disruptions negatively impacting the employees work eventually results in better performance (Spaulding, 2011).

Consequently, policy makers in healthcare industry increasingly recognize that a well-motivated, appropriately skilled and deployed workforce is crucial for the success of health system delivery (Buchan, 2004), managing this workforce by means of human resource management (HRM) can be seen as an important key to success in hospitals. With the recent advances in human resource management, high performance work system (HPWS), which was introduced in the last few decades, is viewed as the use of mutually reinforcing HRM practices in a systematic way which stresses on the selection of suitable employees, development of their skills, organizing work so that employees have the discretion to solve problems creatively, and the use of reward systems which motivate employees to work effectively in pursuit of organizational goals (Harley et al., 2007).

Globally, patient safety has become foremost critical issue in the last decade either in the developed countries or in the developing countries (Nygren et al., 2013). Despite of the growing global concern about patient safety accompanied by the recent advances in medical technologies and several researches' conceptualization of patient safety, the reports and statistics about patient safety are scarce even in developed countries (Shojania et al., 2001). The review of the available statistics clearly points to critical level of patient safety worldwide. For example, the statistics published by the Committee on Quality of Health Care in America and Institute of Medicine (2000) revealed that the annual total deaths due to preventable medical errors in USA were estimated to exceed 44,000 patients. In light of this and other similar alarming statistics from other institutes (Jao\&Hier, 2010), it was ascertained that medical errors not only threaten the quality of healthcare and increase healthcare costs, but it also adds to the medical malpractice crisis (Studdert et al., 2005).

Many researchers emphasized the importance of organizational climate on the accuracy and safety practices in the medical environment. In relation to that, Asha (2008) claimed that organizational climate hinges on the perceptions of the employees, and reflects the manner to which employees acknowledge their work environment, which in turn affects their work-related attitudes and behaviors.

Organizational climate refers to the acknowledged features of the organization and its sub-systems as reflected in its way of dealing with members, groups and issues (Asha, 2008). It is a set of measurable properties of the work environment, which is directly and indirectly perceived by the individuals at the workplace and assumed to affect their motivation and behavior (Litwin\& Stringer, 1968). Based on this definition, organizational climate may be described as the individual's attitude towards organizations (e.g., trust level, morale, conflict, rewards equity, leadership credibility, change resistance and scapegoating (Ngo et al., 2009).

Some researchers have nevertheless postulated that climate is an environmental attribute that is developed by the organization's objective characteristics like its structure context. For instance, according to Richers and Schneider (1990), climate consists of the organization's perceptions concerning rewards (formal or informal), policies, routines, practices and procedures. The description of climate as an objective attribute indicates that an outside person can measure the climate in the organization on the basis of its aspects. Based on this notion, individual perceptions of climate should be ignored and this goes against the traditional method of aggregating individual's perception to measure climate. If climate is an actual organizational characteristic, then totaling individual data to gauge climate may lose its appropriateness (Glick \& Roberts, 1984).

The mediating effect of organizational climate on the relationship between HRM system strength and organizational performance was first proposed by Bowen and Ostroff (2004). Sanders et al. (2008) stated that a strong organizational climate was a term used by Bowen and Ostroff (2004) to refer to the climate strength and not its level. Climate level refers to the convergent perceptions ratings of particular work situation facet like safety, service, or HRM. It is often measured by the mean of individual perception scores, whereas climate strength refers to the agreement level concerning the climate. Climate strength is measured via homogeneity statistics that relate to the aggregate members' perception like standard deviation and within-group correlations. Hence, climate strength more closely reflects Bowen and Ostroff's (2004) organizational climate concept as the shared perceptions of employees.

Finally, in the health care sector, the environment has bearing on outcomes such as patient safety (Ngo et al., 2009). The dynamic work environment is what forms the organizational climate of the health service organization and it forms a guideline upon which employees to understand organizational life in the health care organizations (Ngo et al., 2009). Thus, organizational climate can be deemed among the top mediating factors in patient safety context (Walston et al., 2010). Such mediation arises via HRM. Although several aspects related to HRM can impact patient safety, the present study focuses on specific elements that impact nurses' practices in public hospitals and its effect on patient safety.

Therefore, the objective of the study is to examine the mediating effect of organizational climate in the 
transformational leadership and patient safety relationship in Saudi public hospitals.

\section{Literature Review and Hypothesis Development}

\subsection{Transformational Leadership}

Leadership refers to the power of the individual to influence other individuals (Tappen, Weiss, \& Whitehead, 2004) and to encourage them to develop and achieve common aims (Richardson \&Storr, 2010). Transformational leadership is the leadership style when leaders act in an attempt to maximize the awareness of their associates of what is right and important, to increase their motivational maturity and to move them to see beyond their self-interests for the sake of the group, the organization and the society as a whole. In this context, Transformational leaders promote their associate's sense of purpose that goes beyond the reward for effort exchange (Bass \&Avolio, 1997).

Predominant studies in this field have concentrated on transformational leadership theory (Bass, 1985; Burns, 1978) when assigning leaders within the categories of leadership. Stated differently, majority of studies that have attempted to analyze potential relationships between leadership behavior through MLQ-5X and safety outcomes, concentrated on the cultural elements of safety rather than directly measuring its outcomes, namely, injuries and accidents. Accordingly, Barling et al. (2002) brought forward a model demonstrating the potential association between safety-related outcomes (occupational injury) and behaviors of transformational leadership. This is followed by Kelloway et al.'s (2006) study that presented the potential existence of a direct association between transformational leadership behaviors and outcomes. Despite the extensiveness of both studies, they lacked generalizability as they both assessed young workers in the context of a low-hazard industry. As mentioned earlier, researches dedicated to evaluating the relationship between transformational leadership behaviors and safety-related outcome variables like frequency and severity of injury in the context of health care institutions are still few and far between.

With regards to transformational leaders, Bass and Avolio (1994) attributed them with idealized influence, inspirational motivation, intellectual stimulation and individualized consideration. The above attributes enable transformational leaders to drive individuals working for them in a manner that they act long-term self-development as opposed to short-term. This type of leaders also urges followers to go beyond personal self-interests for the sake of the group, organizational and society as a whole and concentrate on the most critical aspects of their work and life (Bass, 1990).

In conflict with popular opinion, leadership is significantly different from management and while organizations are open to defining management skills for a specific position, they failed to identify leadership skills/attributes needed for the same position. This may be attributed to the fact that the predictive value of the leadership attributes in guaranteeing operational success in terms of organizational outcomes is still ambiguous. Thus, while tacit consensus exists for the effect of leadership behaviors on organizational outcomes like those linked to safety, there is still lack of understanding of the way these behaviors impact outcomes (Joseph \&Steensm, 2012). The initial step in determining the effect of these behaviors on the outcomes is to distinguish between leadership and management and to define leadership behaviors on the basis of leadership theories.

It is well known that in majority of organizations, managers are appointed to provide leadership but managers are mostly involved in laying down processes, overlooking tasks and assessing progress. On the other hand, leadership is described as a relationship with different facets involving associations between leaders and followers (Hirtz, Murray, \& Riordan, 2007; Kark\& van Dijk, 2007). A leader's primary task is to transform his/her followers into future leaders (Taylor, 2003). Another critical difference between leaders and managers is that the former basically provides vision, sets values and mission and lays down goals (Clovard, 2003). Additionally, leadership is a concept that is related to an enhanced future state while management is a concept that is related to the maintenance of an efficient present state. Moreover, managers are appointed to their position, while leaders are granted a role by their followers to influence the latter's actions (McLean, 2005). However, this does not mean that managers cannot be leaders.

In fact, managers often lead but the difference lies in the way they perform their duties - whether they are leading or managing. Groom (2006) claimed that a person manages when he acts according to authoritative procedures and a person leads when he acts according to what is right. It is noteworthy that both managers and leaders are critical to the dynamic of the organization and should not be set against each other but considered in tandem to achieve tasks and cast a vision providing the constructs for an enhanced future state. For instance, if the organization has a vision of enhancing overall occupational safety performance but does not have the systems, processes and outcome measures to manage it, the vision will just be a dream. Similarly, if the organization has the systems, process and outcome measures but does not have a leader to drive people into action, the vision will be left unrealized. However, this does not indicate that all 
leadership or management methods are effective in every situation. According to many studies, different leadership behaviors have different impacts in terms of outcomes and safety-related variables (e.g., Kelloway et al., 2006; Clarke \& Ward, 2006; Barling et al., 2002; Groom, 2006; Luria, 2008). This literature review does not intend to explain every nuance of the differences between leadership and management but to explain that managing and leading are distinct from each other and to clarify that how people lead as managers can impact the ability of the organization to achieve an improved future state.

\subsection{Transformational Leadership, Patient Safety and Organizational Climate}

The literature addresses the significance of leadership and its role in developing an environment and a system of safety within the organization. According to Baker and Norton (2001), a leader's role is important in the development of a patient safety plan. Similarly, Leape and Berwick (2000) stated that leadership is the main element of success in the safety realization, and that lack of commitment from professional and organizational leaders will achieve fragmented and uncoordinated efforts that will barely make a difference. Thus, they urged senior leaders to stress safety as an organizational goal and reinforce it with suitable resources in way that they feel personally accountable for each error.

On the same note, Pater (2006) maintained that organizational leaders have key impact on safety performance. This assertion is corroborated by empirical studies on the relationship between transformational leadership behaviors and safety outcomes that are linked to safety culture (e.g. Barling, Loughlin, \&Kelloway, 2002; Groom, 2006; Zohar \& Luria, 2004). The premise is that behaviors of leaders affect the safety climate and culture, which in turn influences the outcome measures related to safety performance (Barling et al., 2002). Despite the significant studies dedicated to safety climate and safety culture in various industrial settings, there is still lack of consensus concerning the definitions of safety climate and culture (Wiegmann, Zhang, von Thaden, Sharma, \& Mitchell-Gibbons, 2004). But even in the face of this lack in consensus, several studies have been conducted to compare leadership behaviors with safety climate and culture measures (e.g., Clark, 2006; Erickson, 2008; Groom, 2006; Hoffman \&Morgeson, 1999; Kelloway, Mullen, \& Francis, 2006; Luria, 2008; Simon \& Frazee, 2005; Watson, Bishop, \&Trunbeaugh, 2005; Zohar, 2002; Zohar \& Luria, 2004).

Despite the strong belief among researchers that many aspects of patient safety are predicted by the performance of the executive leaders, it is difficult to provide evidence for such claim especially when studies are conducted in isolation from other organizational variables (Bonnie, 2008). Leaders influence employees' performance in two ways: first, indirectly through their choice and design of management control systems and practices and, second, through their influence on employee behavior via behaviors such as, leading by example, and recognizing achievements (Boedker, Vidgen, \& Meagher, 2011). In this respect, it is the influence of the leader on choice and design of management system what concern; leaders are responsible for generating vision, setting values and putting the overall objectives (Clovard, 2003) that will be the responsibility of the managers to achieve it.

According the above arguments and other supporting ones, the following hypotheses were introduced for empirical test.

$H_{1}:$ Transformational Leadership has a positive impact of Patient Safety in an organization.

$\mathrm{H}_{2}$ : Transformational Leadership positively affects the Organizational Climate in an organization.

\subsection{Organizational Climate}

Organizational climate refers to the acknowledged features of the organization and its sub-systems as reflected in its way of dealing with members, groups and issues (Asha, 2008).. Asha (2008) claimed that organizational climate hinges on the perceptions of the employees, and reflects the manner to which employees acknowledge their work environment, which in turn affects their work-related attitudes and behaviors. Based on this definition, organizational climate may be described as the individual's attitude towards organizations (e.g., trust level, morale, conflict, rewards equity, leadership credibility, change resistance and scapegoating (Burton et al., 2004; Ngo, Foley, \&Loi, 2009).

The first group of theorists including Glick (1988) and James (1982) contended that organizational climate is the individual's property, meaning it refers to the individual's perception concerning the norms and characteristics of the organization. Stated differently, organizational climate has its basis on its members' interactions. The second group of theorists (Friedlander \&Marguiles, 1969; Schneider, 1985; Schneider \& Reichner, 1983) opined that organizational climate is an organization's objective property, which are organizational policies and practices. This group of theorists believes that it is an organizational attribute as opposed to an individual attribute, despite the organizational members' perceptions. On the other hand, James and Jones (1974) stated that organizational climate may be used synonymously with psychological climate - a term that has been evaluated at par with disengagement, hindrance, esprit, intimacy, 
aloofness, production emphasis, consideration and trust.

Organizational Climate and Patient Safety

In general, organizational climate is a set of measurable properties of the work environment, which are directly and indirectly perceived by the individuals at the workplace and assumed to affect their motivation and behavior (Litwin\& Stringer, 1968).

Many scholars believe that organizational climate is a significant factor in ensuring patient safety in health care systems (Asha, 2008; Walston, Al-Omar,\& Al-Mutari, 2008). Basically, climate is a term that indicates shared employee perceptions which directly influences health care professionals to choose proper behaviors that enhance patient safety (Walston, Al-Omar,\& Al-Mutari, 2008). From this definition, it is clear that the concept of organizational climate in health care systems is intimately related to patient safety. Hence, there is a growing concern about the impact of certain aspects of organizational climate on work stress and subsequent adverse events (Clarke, Rockett, Sloane, \& Aiken, 2002; Gershon et al., 2000). For instance, Fogarty and McKeon (2006) tested a model with hypothesized links between organizational climate and unsafe medication administration among nurses in Australia. They found that the model provided a considerable fit to the data with organizational climate and its relationship with the magnitude of violations to instructions. In an international study aimed at investigating perception of the nurses about the organizational climate; it was found that nurses who were deprived from supportive climate are usually have lower insight about the safety climate (Malloy et al., 2009). In another quasi experimental study it was found that changing climate was associated with changes in performance and number of nosocomial infections (Larson, Early, Cloonan, Sugrue, \&Parides, 2000).

This justifies the empirical examination of the following hypotheses.

$\mathrm{H}_{3}$ : Organizational Climate has a positive effect on Patient Safety in an organization

$H_{4}$ : Organizational Climate mediates the relationship between Transformational Leadership and Patient Safety in an organization.

\section{Research Framework}

In line with the literature review and the hypothesis development as presented in the previous sections, Figure 1 presents the overall representation of the theoretical framework. The framework of the study depicts the relationships between leadership, Transformational Leadership, organizational climate and Perception of patient safety. Based on the fragmented empirical evidence, the current study suggests a coherent model investigating these relationships in a single model.

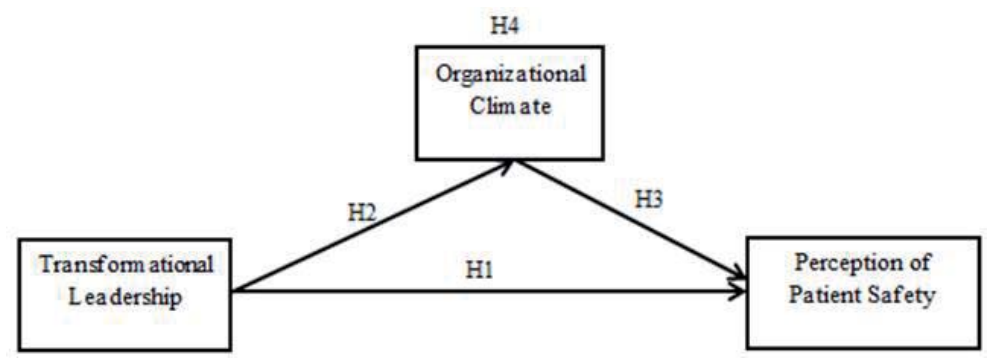

Figure 1: Research Framework

\section{Measurements of Instruments}

The measurements of Transformational Leadership were derived from the relevant studies. However, the deployed measure used in this study was adapted from the measures used by Avolio and Bass, (1995). The measurement of Organizational Climatewas adopted from Burton et al., (2004) and the measurement of Perception of Patient Safety was adapted from Ramanujam et al. (2007) and Teng et al. (2009).

\section{Data Analysis and Results}

\subsection{Testing the Measurement Model, Outer Model, Using PLS Approach}

As it is the norm in Structural Equation Modeling literature, before testing the hypothesis the measurement model should 
be proved having a adequate validity and reliability levels. In this study, the construct validity and reliability were confirmed through the convergent and discriminant validity as discussed in the following paragraphs.

The convergent validity refers to the extent to which a set of items designed to measure a construct converge to measure the intended construct. It was examined by calculating the loadings, Average Variance Extracted (AVE) and Composite Reliability (CR) and assessing them with comparison to the cut-off values suggested by the literature. In assessing the outputs, Table 1 shows that factor loading are more than 0.5 for all items without any correlation between items. The composite reliability values ranged from 0.860 to 0.913 . These values exceeded the recommended value of 0.7 (Fornell \& Larcker, 1981; Hair et al., 2010). The average variances extracted (AVE) values ranged between 0.605and 0.793, indicating a good level of construct validity of the measures used (Barclay et al., 1995). Hence, these results confirm the convergent validity of the outer model.

Table 1. Convergent Validity of the Outer Model

\begin{tabular}{|c|c|c|c|c|c|}
\hline Variable & Items & Factor Loading & Cronbach's Alpha & $\mathrm{CR}^{\mathrm{a}}$ & $\mathrm{AVE}^{\mathrm{b}}$ \\
\hline \multirow[t]{4}{*}{ Individualized consideration. } & 117 & 0.763 & 0.836 & 0.891 & 0.673 \\
\hline & 118 & 0.893 & & & \\
\hline & 119 & 0.822 & & & \\
\hline & 120 & 0.798 & & & \\
\hline \multirow[t]{4}{*}{ Idealized influence (attribute) } & I1 & 0.854 & 0.867 & 0.909 & 0.714 \\
\hline & 12 & 0.771 & & & \\
\hline & 13 & 0.896 & & & \\
\hline & 14 & 0.853 & & & \\
\hline \multirow[t]{4}{*}{ Idealized influence (behavior) } & 15 & 0.660 & 0.852 & 0.902 & 0.700 \\
\hline & 16 & 0.894 & & & \\
\hline & 17 & 0.881 & & & \\
\hline & 18 & 0.889 & & & \\
\hline \multirow[t]{4}{*}{ Inspirational motivation } & 19 & 0.894 & 0.913 & 0.939 & 0.793 \\
\hline & 110 & 0.863 & & & \\
\hline & I11 & 0.929 & & & \\
\hline & I12 & 0.873 & & & \\
\hline \multirow[t]{4}{*}{ Intellectual stimulation } & 113 & 0.819 & 0.889 & 0.923 & 0.751 \\
\hline & 114 & 0.898 & & & \\
\hline & 115 & 0.855 & & & \\
\hline & I16 & 0.893 & & & \\
\hline \multirow[t]{5}{*}{ Organizational Climate } & $\operatorname{clim} 1$ & 0.931 & 0.867 & 0.899 & 0.605 \\
\hline & clim2 & 0.674 & & & \\
\hline & clim3 & 0.661 & & & \\
\hline & clim4 & 0.901 & & & \\
\hline & clim6 & 0.847 & & & \\
\hline \multirow[t]{4}{*}{ Perception of Patient Safety } & saft1 & 0.761 & 0.764 & 0.860 & 0.675 \\
\hline & saft2 & 0.877 & & & \\
\hline & saft3 & 0.652 & & & \\
\hline & saft7 & 0.567 & & & \\
\hline
\end{tabular}

\subsection{Discriminant Validity of the Measures}

The other indicator of the construct validity and reliability is to confirm the discriminant validity. It refers to the ability of a set of measuring items to differentiatetheir respective construct from other constructs in the model. The discriminant validity of the measures was confirmed by employing the method of Fornell and Larcker (1981). As illustrated in Table 2, the square root of average variance extracted (AVE) for all the constructs were placed at the diagonal elements of the correlation matrix. As the diagonal elements were higher than the other elements of the row and column in which they were located, this confirms the discriminant validity of the outer model.

In sum, having established the construct validity of the outer model, it is assumed that the obtained results pertaining to the hypotheses testing should be valid and reliable. 
Table 2: Discriminant Validity Results

\begin{tabular}{llllllll}
\hline Contracts & 1 & 2 & 3 & 4 & 5 & 6 & 7 \\
\hline 1) Individualized consideration. & $\mathbf{0 . 8 2 0}$ & & & & & & \\
2) Idealized influence (attribute) & 0.701 & $\mathbf{0 . 8 4 5}$ & & & & & \\
3) Idealized influence (behavior) & 0.825 & 0.862 & $\mathbf{0 . 8 3 7}$ & & & & \\
4) Inspirational motivation & 0.873 & 0.722 & 0.865 & $\mathbf{0 . 8 9 0}$ & & & \\
5) Intellectual stimulation & 0.907 & 0.692 & 0.838 & 0.865 & $\mathbf{0 . 8 6 7}$ & & \\
6) Organizational Climate & 0.566 & 0.657 & 0.673 & 0.723 & 0.599 & $\mathbf{0 . 7 7 7}$ & $\mathbf{0 . 8 2 2}$ \\
7) Perception of Patient Safety & 0.204 & 0.517 & 0.434 & 0.466 & 0.356 & 0.627 & \\
\hline
\end{tabular}

\section{The Structural Model and Hypothesis Testing}

After the measurement model has been established, the next step was to test the hypotheses of the study by running PLS Bootstrapping in SmartPLS 2.0, . The results were reported in Table 3 and Figure 2 and Figure 3.

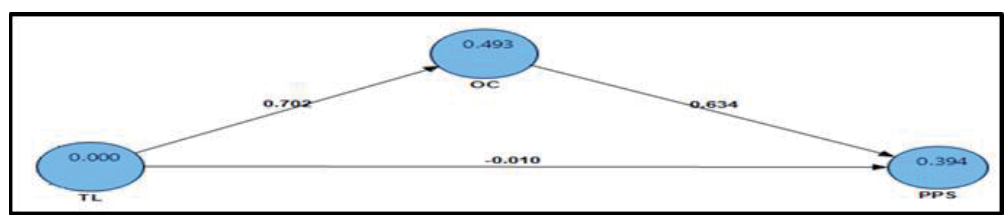

Figure 2: Path Coefficient Result

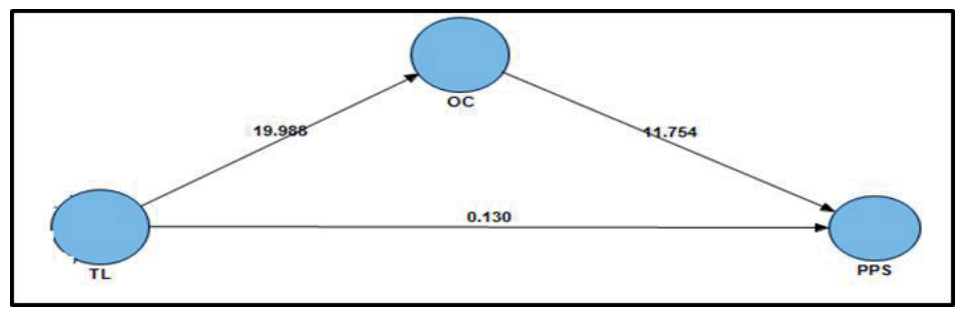

Figure 3: Path Coefficients T values

Table 3: The Results of the Hypothesis Testing

\begin{tabular}{ccccccc}
\hline Hyp No & Hypothesis & Path Coefficient & Standard Error & T Value & P Value & Decision \\
\hline H3 & OC -> PPS & 0.634 & 0.054 & 11.754 & 0.000 & Supported \\
H2 & TL -> OC & 0.702 & 0.035 & 19.988 & 0.000 & Supported \\
H1 & TL - P PPS & -0.010 & 0.078 & 0.130 & 0.448 & Not Supported \\
\hline
\end{tabular}

The statistical results, as presented in Table 3 , show that the influence of transformational leadership on the perception of patient safety was negative and insignificant $(\beta=-0.010, t=0.130, p>0.1)$ and thus the hypothesis $H 1$ is not supported. However, the results pertaining to the effect of Transformational Leadership on Organizational Climate and the effect of Organizational Climate on Patient Safety showed that the two effects were confirmed at the 0.001 level of significance with indicators $(\beta=0.634, t=11.754, p<0.001)$ and $(\beta=0.702, t=19.988, p<0.001)$ respectively. These results indicate that while $\mathrm{H}_{1}$ was not supported, $\mathrm{H}_{2}$ and $\mathrm{H}_{3}$ were not.

\section{Testing the Mediating Effect of Organizational Climate}

A mediator variable is considered is the variable that develops an indirect effect through which the focal independent variable influences the criterion variable under study (Baron \& Kenny, 1986). Moreover, Kenny and Little (2011) stated that the mediator variable is capable of transmitting some causal effects of previous variables on to the next ones. Furthermore, mediating variables have been playing a key role in both psychological theory and research. 
In testing the mediation effect of the Organizational Climate on the said relationship, the direct effect between the two ends of the relationship was tested. That is the effect of Transformational Leadership on Patient Safety was examined when the Organizational Climate is not accounted for was calculated and found to be significant at the 0.001 level of significance $(\beta=0.441, t=10.564, p<0.001$ ). This finding confirms that the Organizational Climate is a full mediator between the Transformational Leadership and Patient Safety according to Baron and Kenny (1986). Thus $\mathrm{H}_{4}$ was supported.

To confirm the existence of the existence effect of Organizational Climate, the bootstrapping method was used to calculate the indirect effect an its significance. Table 5 showed that the indirect effect is significant at the 0.001 level of significance $(\beta=0.445, t=9.101, p<0.01)$. a full mediation effect of organization climate on the relationship between transformational leadership and the perception of patient safety $(\beta=0.445, t=9.101, p<0.01)$..

This result implies that organization climate acts as the mechanism that can explain the indirect effect of transformational leadership on the perception of patient safety.

Table 4: The Mediation Analysis Results

\begin{tabular}{|c|c|c|c|c|c|c|c|c|}
\hline \multirow{2}{*}{$\begin{array}{l}\text { Hyp. } \\
\text { No }\end{array}$} & \multirow[b]{2}{*}{ Hypothesis } & \multicolumn{2}{|l|}{$a * b$} & \multicolumn{2}{|l|}{$C$} & \multicolumn{2}{|l|}{$c^{\prime}$} & \multirow{2}{*}{$\begin{array}{c}\text { Decision } \\
\text { (bootstrapping } \\
\text { Method) }\end{array}$} \\
\hline & & Path Coefficient & T.Value & Path Coefficient & T.Value & Path Coefficient & $\begin{array}{l}\text { T.Va } \\
\text { lue }\end{array}$ & \\
\hline $\mathrm{H}_{4}$ & & 0.445 & 9.101 & 0.441 & 10.564 & -0.01 & 0.13 & Full Mediation \\
\hline
\end{tabular}

\section{Predictive Relevance, the Quality, of the Model}

The quality of the model can be assessed through the $\mathrm{R}^{2}$ values of the endogenous variables. The results in Table 5 indicate that Transformational Leadership can explain $49 \%$ of the variance in Organizational Climate and both Transformational Leadership and Organizational Climate explain 39\% of the variance of the Perceived Patient Safety.

Further, the results of the study related to the prediction quality of the model, as illustrated in Table 3 indicated that the cross-validated redundancy of Organizational Climate and Perception of Patient Safety were 0.285and 0.238 respectively.more than zero indicating an adequate predictive validity of the model based on the criteria suggested by Fornell and Cha (1994).

Table 5: Predictive Relevance of the Model

\begin{tabular}{lccc}
\hline Endogenous & R Square & Cross-Validated Redundancy & Cross-Validated Communality \\
\hline Organizational Climate & 0.493 & 0.285 & 0.604 \\
Perception of Patient Safety & 0.394 & 0.238 & 0.604 \\
\hline
\end{tabular}

\section{Discussion and Conclusion}

\subsection{Transformational Leadership and Organizational Climate}

Our finding showed that transformational Leadership had a positive significant impact on organizational climate. This means that transformational leadership is able to develop or improve appropriate organization climate. The finding is in line with previous studies. For example, Jung, Chow, and Wu (2003) examined the relationship between style of leadership and organizational climate, as a mediator of organizational innovation among 32 Taiwanese companies. They found that transformational leadership had a significant and positive relation with both empowerment and an innovationsupporting organizational climate. Similar result was also reported by Sarros, Cooper, and Santora (2008), who revealed that transformational leadership affected organizational climate. In Turkey, Gumusluoglu and Ilsev (2009) revealed that transformational leadership was positively associated with organizational innovation and supported organizational climate. Koene, Vogelaar, and Soeters (2002) also found similar finding when found a positive relationship between transformational leadership and organizational climate in the Netherlands.

In addition, Transformational leadership theory postulates that a transformational leader is capable of shaping the climate of an organization because he/she shares values and beliefs with the followers, developing and creating a climate of trust with confidence. Such leader is also capable of inspiring the followers to have a positive attitude and to be able to solve problems (Bass \&Avolio, 1995). 


\subsection{Organizational Climate and the Perception of Patient Safety}

The result revealed that organizational climate had a positive significant influence on patient safety. Clarke and Donaldson (2008) argued that a non-punitive organizational climate is expected to encourage reporting system. In a different study in Turkey, Bodur and Filiz (2010) found that the non-punitive climate was associated with perception of physicians and nurses about patient safety. Similar finding was also reported by Malloy et al. (2009) in their study that covered four countries (Canada, Ireland, Australia, and Korea). They found that nurses deprived of supportive climate usually had lower insight about safety climate.

The high reliability organization theory include dimensions which are essentially could describe the perception of the health professionals about the safety climate within their hospital; for example "redundancy" which refer to ability of employees to detect errors before it occur (vigilance), which are usually deployed under feeling of "trust" and supported by training to provide higher degree of safety (Weick et al., 2005; Sutcliffe, 2006).

\section{References}

Aiken, L. H., Clarke, S. P., Cheung, R. B., Sloane, D. M., \& Silber, J. H. (2003). Educational levels of hospital nurses and surgical patient mortality. JAMA, 290(12), 1617-1623.

Al Rifai, F. (2008). Nurse Executives' Perception of Barriers and Facilitator.

Asha, S. (2008). Organizational Climate and Employee Health. Journal of Organizational Behavior.

Barling, J., Kelloway, E. K., \& Iverson, R. D. (2003). High-quality work, job satisfaction, and occupational injuries. Journal of Applied Psychology, 88(2), 276.

Baron, R. M., \& Kenny, D. A. (1986). The moderatorG_ômediator variable distinction in social psychological research: Conceptual, strategic, and statistical considerations. Journal of personality and social psychology, 51(6), 1173.

Bass, B. M. (1990). Bass \& Stogdill's handbook of leadership; theory, research, and managerial applications New York: The Free Press.

Boedker, C., Vidgen, R., \& Meagher, K. (2011). Leadership, Culture and Management Practices of High Performing Workplaces in Australia: The High Performing Workplace Index.

Buchan, J. (2004). What difference does ("good") HRM make? Human Resources for Health, 2(6), 1-7.

Burns, J.M. (1978) Leadership. New York. Harper \& Row, Onursal Arkan.

Burton, R. M., Lauridsen, J., \& Obel, B. (2004). The impact of organizational climate and strategic fit on firm performance. Human Resource Management, 43(1), 67-82.

Chow, W.S., \& Chan, L.S. (2008). Social network, social trust and shared goals in organizational knowledge sharing. Information \& Management, 45(7): 458-465.

Clarke, J. R. (2006). How a system for reporting medical errors can and cannot improve patient safety. The American Surgeon, 72(11), 1088-1091.

Committee on Quality of Health Care in America \& Institute of Medicine. (2000).

Fogarty, G. J., \& McKeon, C. M. (2006). Patient safety during medication administration: the influence of organizational and individual variables on unsafe work practices and medication errors. Ergonomics, 49(5-6), 444-456.

Fornell, C., \& Larcker, D.F. (1981). Evaluating structural equation models with unobservable variables and measurement error. Journal of marketing research, 39-50.

Gershon, R. R., Karkashian, C. D., Grosch, J. W., Murphy, L. R., Escamilla-Cejudo, A., Flanagan, P. A. et al. (2000). Hospital safety climate and its relationship with safe work practices and workplace exposure incidents. Am.J Infect Control, 28(3), 211-221.

Glick, W. H. (1985). Conceptualizing and measuring organizational and psychological climate: Pitfalls in multilevel research. Academy of Management Review, 601-616.

Hair, J.F., Anderson, R.E., Tatham, R.L. \& Black, W.C. (2010), Multivariate Data Analysis. 7th Ed. Prentice Hall : USA.

Hair, JF, Black, WC, Babin, BJ, \& Anderson, RE. (2010), Multivariate data analysis: a global perspective: Pearson Education.

Harley, B., Allen, B. C., \& Sargent, L. D. (2007). High performance work systems and employee experience of work in the service sector: The case of aged care. British Journal of Industrial Relations, 45(3), 607-633.

Harley, B., Allen, B. C., \& Sargent, L. D. (2007). High performance work systems and employee experience of work in the service sector: The case of aged care. British Journal of Industrial Relations, 45(3), 607-633.

James, L. R., \& Jones, A. P. (1974). Organizational climate: A review of theory and research. Psychological bulletin, 81(12), 1096.

Jao, C. S., \& Hier, D. B. (2010). Clinical Decision Support Systems: An Effective Pathway to Reduce Medical Errors and Improve Patient Safety. Future, 4, 4.

Larson, E. L., Early, E., Cloonan, P., Sugrue, S., \& Parides, M. (2000). An organizational climate intervention associated with increased handwashing and decreased nosocomial infections. Behavioral Medicine, 26(1), 14-22.

Leape, L. L., Berwick, D. M., \& Bates, D. W. (2002). What practices will most improve safety? JAMA: the journal of the American Medical Association, 288(4), 501-507.

Litwin, G. H., \& Stringer Jr, R. A. (1968). Motivation and organizational climate.

Ngo, H. y., Foley, S., \& Loi, R. (2009). Family friendly work practices, organizational climate, and firm performance: A study of multinational corporations in Hong Kong. Journal of Organizational Behavior, 30(5), 665-680. 
Nygren, M., Roback, K., Ohrn, A., Rutberg, H., Rahmqvist, M., \& Nilsen, P. (2013). Factors influencing patient safety in Sweden: perceptions of patient safety officers in the county councils. BMC health services research, 13(1), 52.

Nygren, M., Roback, K., Ohrn, A., Rutberg, H., Rahmqvist, M., \& Nilsen, P. (2013). Factors influencing patient safety in Sweden: perceptions of patient safety officers in the county councils. BMC health services research, 13(1), 52.

Penoyer, D. A. (2010). Nurse staffing and patient outcomes in critical care: a concise review. Crit Care Med., 38(7), 1521-1528.

Ramanujam, R., Abrahamson, K., \& Anderson, J. (2007). Influences on nurse perception of hospital unit safety climate: an HLM approach. RCHE Publications, 34.

Richardson, A., \& Storr, J. (2010). Patient safety: a literature [corrected] review on the impact of nursing empowerment, leadership and collaboration. Int Nurs Rev., 57(1), 12-21.

Schneider, B. (1990). The climate for service: An application of the climate construct. Organizational climate and culture, 1. $383-412$. San Francisco: Jossey-Bass.

Shojania, K. G., Duncan, B. W., McDonald, K. M., Wachter, R. M., \& Markowitz, A. J. (2001). Making health care safer: a critical analysis of patient safety practices Agency for Healthcare Research and Quality Rockville, MD.Springer.

Shojania, K. G., Duncan, B. W., McDonald, K. M., Wachter, R. M., \& Markowitz, A. J. (2001). Making health care safer: a critical analysis of patient safety practices Agency for Healthcare Research and Quality Rockville, MD.

Spaulding, A. C. (2011). Human resource management systems: The search for quality and effectiveness in healthcare delivery (Doctoral dissertation, The Texas A\&M University System Health Science Center.

Studdert, D. M., Mello, M. M., Sage, W. M., DesRoches, C. M., Peugh, J., Zapert, K. et al. (2005). Defensive medicine among high-risk specialist physicians in a volatile malpractice environment. JAMA: the journal of the American Medical Association, 293(21), 2609-2617.

Sutcliffe, W. (2006). Managing the unexpected: assuring high performance in an age of complexity. John Wiley \& Sons.

Tappen, R. M., Weiss, S. A., \& Whitehead, D. K. (2004). Essentials of nursing leadership and management. 3rd. Edition.Philadelphia: EA Davis Company.

Teng, C. I., Chang, S. S., \& Hsu, K. H. (2009). Emotional stability of nurses: impact on patient safety. J Adv.Nurs, 65(10), $2088-2096$.

Walston, S. L., Al-Omar, B. A., \& Al-Mutari, F. A. (2010). Factors affecting the climate of hospital patient safety: A study of hospitals in Saudi Arabia. International Journal of Health Care Quality Assurance, 23(1), 35-50.

Walston, S., Al-Harbi, Y., \& Al-Omar, B. (2008). The changing face of healthcare in Saudi Arabia. Ann.Saudi Med., 28(4), $243-250$.

Weick, K. E., Sutcliffe, K. M., \& Obstfeld, D. (2005). Organizing and the process of sensemaking. Organization science, 16, 409-421.

World Health Organization (2004). Global priorities for patient safety research. WHO. Ref Type: Generic.

World Health Organization. (2009). WHO Patient Safety Curriculum Guide for Medical Schools. WHO/IER/PSP/2009.3S.

Zohar, D. (2002). The effects of leadership dimensions, safety climate, and assigned priorities on minor injuries in work groups. Journal of Organizational Behavior, 23(1), 75-92. 